Full length article

\title{
Exposure to fine particle matter, nitrogen dioxide and benzene during pregnancy and cognitive and psychomotor developments in children at 15 months of age
}

\author{
Aitana Lertxundi a,b ${ }^{\text {, }}$ Michela Baccini ${ }^{\text {c,d }}$, Nerea Lertxundi ${ }^{\text {b,e }}$, Eduardo Fano ${ }^{\text {b,e }}$, Aritz Aranbarri ${ }^{\text {b,e }}$, \\ Maria Dolores Martínez ${ }^{\text {b,f }}$, Mikel Ayerdi b,h ${ }^{\text {, Jon Álvarez }}{ }^{\mathrm{g}}$, Loreto Santa-Marina ${ }^{\mathrm{b}, \mathrm{h}, \mathrm{i}}$, \\ Miren Dorronsoro ${ }^{\mathrm{b}, \mathrm{h}, \mathrm{i}}$, Jesus Ibarluzea ${ }^{\mathrm{b}, \mathrm{h}, \mathrm{i}, \boldsymbol{}^{\prime}}$ \\ a Faculty of Medicine, University of the Basque Country (UPV/EHU), Leioa, Basque Country, Spain \\ b BIODONOSTIA Health Research Institute, San Sebastian, Basque Country, Spain \\ c Department of Statistics, Informatics and Applications “G. Parenti”, University of Florence, Italy \\ d Biostatistics Unit, Cancer Prevention and Research Institute (ISPO), Florence, Italy \\ e Faculty of Psychology, University of the Basque Country UPV/EHU, San Sebastian, Basque Country, Spain \\ ${ }^{\mathrm{f}}$ Department of the Environment and Regional Planning, Government of the Basque Country, Vitoria, Spain \\ ${ }^{g}$ Public Health Laboratory, Department of Health, Government of the Basque Country, Bilbao, Spain \\ h Sub-Directorate for Public Health of Guipúzcoa, Department of Health, Government of the Basque Country, San Sebastian, Spain \\ i Biomedical Research Centre Network for Epidemiology and Public Health (CIBERESP), Spain
}

\section{A R T I C L E I N F O}

\section{Article history:}

Received 2 July 2014

Received in revised form 14 February 2015

Accepted 2 March 2015

Available online 11 April 2015

\section{Keywords:}

Cognitive development

Psychomotor development

Particle matter

$\mathrm{PM}_{2.5}$

\begin{abstract}
A B S T R A C T
Background: Prenatal exposure to air pollutants has recently been identified as a potential risk factor for neuropsychological impairment.

Objectives: To assess whether prenatal exposure to fine particulate matter $\left(\mathrm{PM}_{2.5}\right)$, nitrogen dioxide $\left(\mathrm{NO}_{2}\right)$ and benzene were associated with impaired development in infants during their second year of life.

Methods: Regression analyses, based on 438 mother-child pairs, were performed to estimate the association between mother exposure to air pollutants during pregnancy and neurodevelopment of the child. The average exposure to $\mathrm{PM}_{2.5}, \mathrm{NO}_{2}$ and benzene over the whole pregnancy was calculated for each woman. During the second year of life, infant neuropsychological development was assessed using the Bayley Scales of Infant Development. Regression analyses were performed to estimate the association between exposure and outcomes, accounting for potential confounders.

Results: We estimated that a $1 \mu \mathrm{g} / \mathrm{m}^{3}$ increase during pregnancy in the average levels of $\mathrm{PM}_{2.5}$ was associated with a -1.14 point decrease in motor score $(90 \% \mathrm{CI}:-1.75 ;-0.53)$ and that a $1 \mu \mathrm{g} / \mathrm{m}^{3}$ increase of $\mathrm{NO}_{2}$ exposure was associated with a -0.29 point decrease in mental score $(90 \% \mathrm{CI}:-0.47 ;-0.11)$. Benzene did not show any significant association with development. Considering women living closer $(\leq 100 \mathrm{~m})$ to metal processing activities, we found that motor scores decreased by $-3.20(90 \% \mathrm{CI}:-5.18 ;-1.21)$ for $\mathrm{PM}_{2.5}$ and $-0.51(-0.89 ;-0.13)$ for $\mathrm{NO}_{2}$, while mental score decreased by $-2.71(90 \% \mathrm{CI}:-4.69 ;-0.74)$ for $\mathrm{PM}_{2.5}$, and -0.41 ( $9 \% \mathrm{CI}:-0.76 ;-0.06)$ for $\mathrm{NO}_{2}$.

Conclusions: Our findings suggest that prenatal residential exposure to $\mathrm{PM}_{2.5}$ and $\mathrm{NO}_{2}$ adversely affects infant motor and cognitive developments. This negative effect could be higher in the proximity of metal processing plants.
\end{abstract}

(C) 2015 Elsevier Ltd. All rights reserved.

\section{Introduction}

Few data are available concerning neuropsychological effects of air pollution on children. Indicators of air pollution used in epidemiological studies related to neurodevelopment in children include exposure to polycyclic aromatic hydrocarbons (PAHs) (Edwards et al., 2010;

\footnotetext{
* Corresponding author at: Avenida de Navarra 4, 20013 Donostia-San Sebastian, Spain. E-mail address: mambien3-san@ej-gv.es (J. Ibarluzea).
}

Perera et al., 2006, 2008, 2009; Tang et al., 2008), particulates of less than $10 \mu \mathrm{m}$ in diameter $\left(\mathrm{PM}_{10}\right)$ (Kim et al., 2014), nitrogen dioxide $\left(\mathrm{NO}_{2}\right)$ (Freire et al., 2010; Guxens et al., 2012a; Guxens et al., 2014; Kim et al., 2014), benzene (Guxens et al., 2012a), and black carbon (Suglia et al., 2007), as well as the distance from their home to the nearest main road with high traffic density (Volk et al., 2013) and the area they live being classified as having a high (versus low) level of pollution (Calderon-Garciduenas et al., 2008; Siddique et al., 2011; Wang et al., 2009). 
PAH levels have been found to be inversely related to mental scale scores in 3-year-olds and to full-scale and verbal IQ scores in 5-yearolds in a prospective birth cohort from New York (Perera et al., 2006, 2009) and to non-verbal intelligent quotient (IQ) in 5-year-olds in Poland (Edwards et al., 2010). Further, PAH-DNA adducts used as indicators of traffic-related pollution have been found to be inversely correlated with psychomotor development and full-scale IQ in 2-year-olds living in the zone with the greatest exposure to coal-fired power plant emissions in China (Perera et al., 2008; Tang et al., 2008). Exposure to black carbon estimated on the basis of children's place of residence was analysed in a birth cohort study carried out in Boston. A significant decrease in full-scale IQ, non-verbal IQ, and visual memory was observed in children around 9 years of age (Suglia et al., 2007). Prenatal exposure to $\mathrm{PM}_{10}$ may result in delayed cognitive and psychomotor developments in early childhood (Kim et al., 2014).

Delayed psychomotor development was found to be associated with $\mathrm{NO}_{2}$ levels in children assessed between 1 and 6 years of age in six European birth cohorts; no effect was seen on cognitive development (Guxens et al., 2014). In four Spanish regions, exposures to $\mathrm{NO}_{2}$ and benzene during pregnancy have been associated with adverse effects on the cognitive development of children of 15 months of age when there was a low maternal intake of fruits and vegetables during pregnancy (Guxens et al., 2012a). Results from a small cohort study in Granada (Spain) analysing exposure to $\mathrm{NO}_{2}$ also indicated reductions in cognitive and psychomotor developments in 4-year-old children (Freire et al., 2010).

Maternal resources during pregnancy play an important role in the physical and mental health of offspring (Bolton et al., 2013; Hackman et al., 2010). Other factors that have been widely studied in relation to their effect on neuropsychological development include maternal IQ (Der et al., 2006), socioeconomic status (Calderón-Garcidueñas and Torres-Jardón, 2012; Hajat et al., 2013) and breastfeeding (Walfisch et al., 2013). Accordingly, analysis of the impact of air pollutants on neurodevelopment must control for the aforementioned variables.

Little is known about possible neurological effects of particle matter in the air. On the other hand, growing interest is being focused on the first years of life due to the susceptibility of the brain to toxicological insults and the importance of this time window for brain development and the decrease in brain plasticity with age (Grandjean and Landrigan, 2006; Sunyer, 2008).

As previously mentioned, Guxens et al. (2012a) found significant associations of $\mathrm{NO}_{2}$ and benzene with infant neurodevelopment in the Spanish cohorts participating to the INMA (INfancia y Medio Ambiente, the Spanish for Childhood and Environment) Project, while the effect of particulate matter has not been explored. In the present work we focused on the INMA birth cohort of the province of Guipúzcoa (the Basque Country, Spain), for which additional information was gathered about maternal exposure to fine particles with an aerodynamic diameter of up to $2.5 \mu \mathrm{m}\left(\mathrm{PM}_{2.5}\right)$ during pregnancy. The aims of our study were to examine: 1) the association of cognitive and psychomotor developments at 15 months of age with exposure to $\mathrm{PM}_{2.5}, \mathrm{NO}_{2}$ and benzene during pregnancy, 2) the role of distance from place of residence to the main industrial activities and roads, and 3) the possible effect modification by breastfeeding duration and maternal antioxidant intake during pregnancy.

\section{Methods}

\subsection{Study area}

The study area covers $519 \mathrm{~km}^{2}$ in the province of Guipúzcoa and spans three narrow valleys: high Urola-Goierri, mid Urola and high Oria. The area has a population of approximately 88,000 inhabitants, spread across 25 small localities (of up to 14,000 inhabitants). At the time of the pregnancies followed-up, the main economic activities in the region were related to the iron and steel industry, with a total of
11 companies in the sector (listed in the 2006 Spanish Register of Emissions and Pollutant Sources, which is the national Pollutant Release and Transfer Register [PRTR]). While this industry contributed significantly to air pollution, another source that needed to be considered was traffic, given that roads with moderate traffic densities (between 10,000 and 40,000 vehicles/day) run through all three valleys.

\subsection{Study design and participants}

A population-based birth cohort was established as part of the INMA Project in several regions of Spain following a common protocol (Guxens et al., 2012b). In the analysis reported in this paper, we consider only the INMA cohort of Guipúzcoa, recruited between May 2006 and January 2008. A total of 638 eligible women ( $\geq 16$ years of age, with intention to deliver at the referral hospital, ability to communicate in Spanish or Basque, singleton pregnancy and non-assisted conception) were recruited during antenatal visits in the first trimester of pregnancy. Cognitive and psychomotor developments of 532 children were assessed at around 15 months of age (range 13-18 months) using the Bayley Scales of Infant Development (BSID) (Bayley, 1977). A total of $9.7 \%(n=52)$ of the test results were excluded from the final analysis due to the poor quality of the child assessments.

Data on exposures, outcomes and potential confounders in this analysis were available for 438 children ( $73.8 \%$ of the children included at birth) (Fig. 1). We included all children living in towns where an air pollution monitor was located, plus 18 children from small towns located in the same valley than Ataun, the so-called "clean town", and having similar air quality profile (towns with no direct influence from any of the sources of pollution). A total of 42 mother-child pairs (8.75\%) were excluded from the analysis because they lived in hilly or mountain areas where the $\mathrm{PM}_{2.5}$ levels did not correspond to those measured in the valley. There were no statistically significant differences in main characteristics between the mother-child pairs included in the analyses and those excluded (Table S1). The study was approved by the hospital ethics committee and all participating mothers provided informed consent.

\subsection{Neuropsychological testing}

The mental scale of the BSID consists of 163 items that assessed ageappropriate cognitive development in areas including performance

\begin{tabular}{c} 
Recruitment, $\mathbf{n}=\mathbf{6 3 8}$ \\
\hline $\begin{array}{c}\text { Lived outside the study area, } \mathrm{n}=10 \\
\text { Withdrew from the study, } \mathrm{n}=12 \\
\text { Foetal deaths, } \mathrm{n}=4 \\
\text { Miscarriages, } \mathrm{n}=10\end{array}$ \\
Date of last menstrual period unknown, $\mathrm{n}=9$ \\
\hline Births, $\mathbf{n = 5 9 3}$ \\
Perinatal deaths, $\mathrm{n}=2$ \\
Withdrew from the study, $\mathrm{n}=10$ \\
\hline $\mathbf{1 5}$ months of age, $\mathbf{n}=\mathbf{5 8 1}$
\end{tabular}

Continued in the study, but did not complete the tests, $n=49$

\begin{tabular}{c} 
Neurological testing, $\mathbf{n = 5 3 2}$ \\
Uncooperative behaviour, $\mathrm{n}=16$ \\
Specific circumstances: sick, tired, hungry or scared, $\mathrm{n}=21$ \\
Neuropaediatric basal disease, $\mathrm{n}=8$ \\
Non-assessable, $\mathrm{n}=7$ \\
\hline DATABASE of child-mother pairs, $\mathbf{n = 4 8 0}$
\end{tabular}

Residence in municipalities without air sampler, $n=42$

DATABASE of this study, $n=438$

Fig. 1. Follow-up of the cohort of pregnant mothers and their children until a mean of 15 months of age. $\mathrm{PM}_{2.5}, \mathrm{NO}_{2}$ and benzene and neuropsychological development. 
ability, memory, and first verbal learning, while the motor scale consists of 81 items, assessing fine and gross motor development. All testing was carried out in health care centres in the presence of the mother, the father or another caregiver by one of two specially trained neuropsychologists who were blinded to the child's exposure status. To minimise inter-observer variability, we applied a strict protocol, including training sessions in which inter-observer differences were discussed (Guxens et al., 2012b). The raw scores were standardised to a mean of 100 points with a standard deviation of 15 points. Higher scores represented better general cognitive and psychomotor developments.

\subsection{Prenatal exposure to $\mathrm{PM}_{2.5}, \mathrm{NO}_{2}$ and benzene}

\subsubsection{Prenatal exposure to $P M_{2.5}$}

Daily levels of $\mathrm{PM}_{2.5}$ were measured from the beginning of the study period until the last birth, using three Digitel DHA-80 high-volume aerosol samplers. Two of the samplers were placed in different towns in the same valley and were rotated monthly between the three valleys. The third device was run continuously at Beasain, a site in the high Oria Valley. In this way, we obtained discontinuous time series of $\mathrm{PM}_{2.5}$ levels in six of the towns, and a continuous time series in one (Beasain). In all cases, the samplers were placed at sites that avoided any direct $\mathrm{PM}_{2.5}$ exposure (from traffic or industry). The maximum distance between samplers in the same valley was 3.5 to $4 \mathrm{~km}$ (Fig. 2). Daily levels of $\mathrm{PM}_{2.5}$ were also available from three continuous fixed-site samplers of the Air Quality Network of the Basque Government located in each of the three valleys. Descriptions of the study area, air pollution monitoring methodology, particle quantification (presented in supplementary Section S1), and air quality in the area have been reported previously (Lertxundi et al., 2010). Notably, the correlation between different instruments located in the same valleys ranged from 0.7 to 0.9 and that between the two instruments located in the same site was over 0.98 .

In order to deal with missing information on $\mathrm{PM}_{2.5}$ levels, due to the rotation of the monitors during the study period, we applied a multiple imputation (MI) procedure. In particular, we employed the approach recently developed by Li et al. (2014), called Multiple Imputation by Ordered Monotone Blocks, that can be seen as a generalisation of the more popular multiple imputation by chained equations approach (MICE) (Van Buuren et al., 2006). See supplementary Section S2 for more detail on the MI procedure.

Women were considered to have been exposed to the $\mathrm{PM}_{2.5}$ levels measured at the monitoring site located in their town or in the closest one. Specifically, each woman was assigned the average concentrations of $\mathrm{PM}_{2.5}$ measured at this site during each of the three trimesters of her pregnancy and during her whole pregnancy.

\subsubsection{Prenatal exposure to $\mathrm{NO}_{2}$ and benzene}

A complete description of the methodology for modelling exposure to $\mathrm{NO}_{2}$ and benzene has been published previously (Iñiguez et al., 2009). Briefly, ambient concentrations of $\mathrm{NO}_{2}$ were repeatedly measured with passive samplers distributed over the study area according to geographic criteria, taking into account the expected pollution gradients. The samplers measured pollutants levels using radial symmetry (Radiello®; Fundazione Salvatore Maugeri, Padua, Italy) and remained exposed during three 7-day sampling periods. Therefore, land use regression (LUR) models were specified on the levels of $\mathrm{NO}_{2}$ measured by the passive samplers, to predict $\mathrm{NO}_{2}$ and benzene levels at the participants' residential addresses. Geographic information system data derived in ArcGIS version 9.1 (ESRI, Redlands, CA, USA) were used to construct predictor variables (distance to the nearest main road and industry, altitude and surface area of urban and industrial zones). $\mathrm{NO}_{2}$ data from monitoring station located in Beasain was used to temporally adjust the LUR estimates to the periods corresponding to each trimester of pregnancy and to the whole pregnancy period.

\subsection{Other maternal and child variables}

Data on the mother's place of birth (Spain, foreign), age, and parity, parental education, social class, maternal vegetable and fruit intake, use of gas cookers at home during pregnancy, maternal alcohol intake, active and passive smoking and marital status were obtained through questionnaires administered during the first and third trimesters of pregnancy. Parental education was described using three categories:
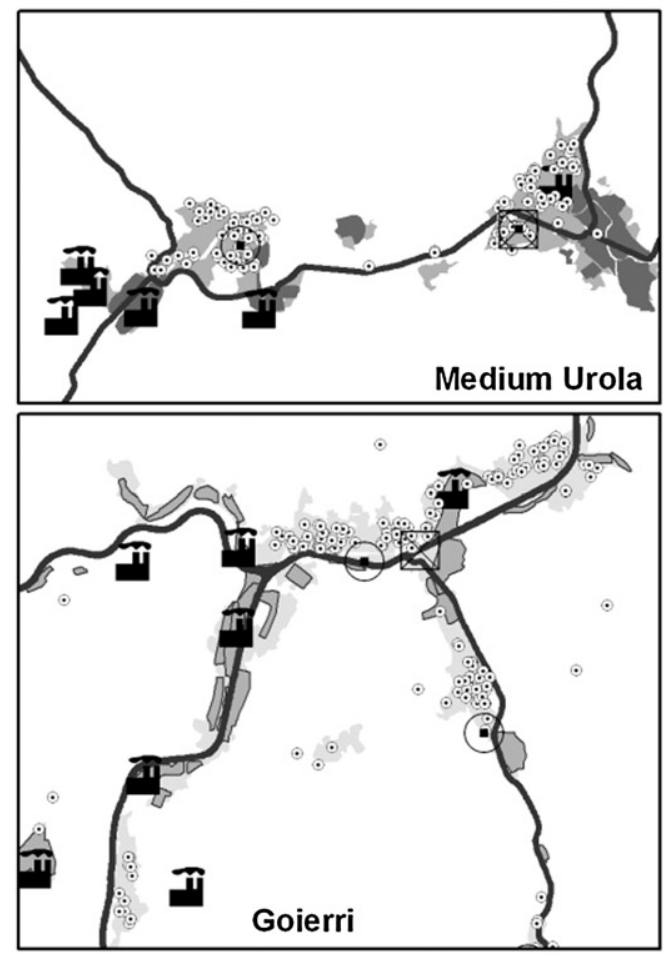

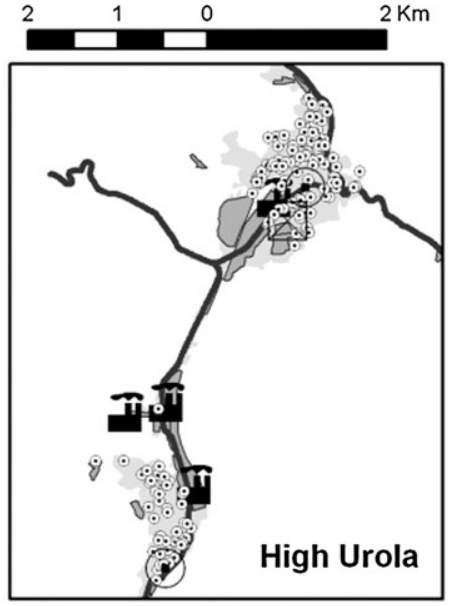

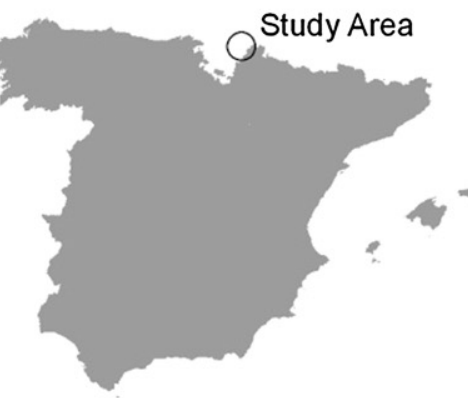

Participants

Samplers

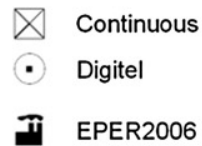

Roads with Average

Daily Traffic $>10.000$

Industrial area

Urban area 
primary or less, secondary school, and tertiary (including university). Maternal social class based on occupation was derived from the longest-held occupation reported during pregnancy or, for those mothers not working during their pregnancy, from the most recent occupation. When social class could not be assessed in this way, the most recent occupation of the father was used. Social class categories were created according to the 1994 National Occupation Codes and regrouped into two categories: I + II + III for managers, technicians, associate professionals and other non-manual workers, and IV $+\mathrm{V}$ for skilled, semi-skilled and unskilled manual workers (Domingo-Salvany et al., 2013). Information on maternal diet was obtained in the first trimester of pregnancy using a 101-item semiquantitative validated food frequency questionnaire (Vioque et al., 2007) (See supplementary Section S3).

Data on the child's gestational age, sex, type of delivery (caesarean section, other), anthropometric measurements, and Apgar score at birth were obtained from clinical records. In a subsequent interview when the child reached 15 months of age, the following data were collected: length of breastfeeding; maternal IQ, by administration of the Similarities subtest of the Wechsler Adult Intelligence Scale - Third Edition (WAIS-III) (Wechsler and Kaufman, 2001); main caregiver of the child (mother, father, other specified relative or caregiver); parental employment status (employed/unemployed), and nursery attendance. All questionnaires were administered face-to-face by one of two trained interviewers. In addition, we had access to data on maternal blood levels of p,p'-DDE and PCBs (PCB 138, 153, and 180 respectively) at the end of the first trimester of pregnancy (Ibarluzea et al., 2011) and cord blood levels of Pb (Llop et al., 2011) and Hg (Ramon et al., 2011). Methods and analytical procedures are described in the corresponding references.

\subsection{Statistical analysis}

Summary statistics for $\mathrm{PM}_{2.5}, \mathrm{NO}_{2}$ and benzene exposure were obtained, including the Pearson's correlation coefficients between exposure during the whole pregnancy and exposure during each of the three pregnancy trimesters. Mean and standard deviations of motor and mental scale scores were calculated for each level of covariates described above. Generalised additive models were used to analyse the crude exposure-response curve for mental and motor scores in respect to exposure (by trimester and for the whole pregnancy). Due to linear functions appropriately described the relationship in almost all cases; the air pollutant level was included in the final models as a linear term. Fig. S1 reports the results for the whole pregnancy.

Multiple linear regression models were specified to investigate the association between neuropsychological scores and exposure to $\mathrm{PM}_{2.5}$, $\mathrm{NO}_{2}$ and benzene, after adjusting for a set of possible confounders selected on the basis of a priori considerations about their relation with outcomes and their observed marginal association with the outcomes themselves ( $p<0.10$ ). The resulting model accounted for child's age when the neuropsychological test was performed, sex, gestational age, maternal parity, social class, breastfeeding duration, maternal vegetable and fruit intake during pregnancy (as a proxy of antioxidant intake) and neuropsychologist. Moreover, in order to adjust for possible misclassification of exposure related to distance from industry and road, in the final model these distances were taken into account through three levels categorical variables (distance $<100 \mathrm{~m}$, distance between 100 and $300 \mathrm{~m}$, distance $>300 \mathrm{~m}$ ). This parameterization allowed us to relax the strong hypothesis of a linear association between distance and outcome. Separate models were specified for $\mathrm{PM}_{2.5}, \mathrm{NO}_{2}$ and benzene. Afterwards, in a sensitivity analysis, the conditional associations of $\mathrm{PM}_{2.5}, \mathrm{NO}_{2}$ and benzene with neuropsychological scores were assessed by specifying bi-pollutant models. Due to the moderately high correlation between $\mathrm{NO}_{2}$ and benzene (Pearson's correlation $\rho=0.74$ ), these two air pollutants have never been included in the same regression model.
In order to investigate possible effect modification by distance from the nearest main road and industry, we included in the regression model interaction terms between distance and exposure, estimating an association for each of the three defined classes of distance. The $\mathrm{p}$-value for the overall significance of the interaction terms was reported.

We investigated also whether the associations of $\mathrm{PM}_{2.5}, \mathrm{NO}_{2}$ and benzene with mental and motor scores were different in: i) children breastfed $\leq 4$ months vs $>4$ months and ii) children whose mothers had fruit and vegetable intakes during their pregnancy ( $\leq 405 \mathrm{~g} /$ day (low tertile) vs $>405 \mathrm{~g} /$ day (medium-high tertile)). Even in this case an appropriate interaction term was included in the regression models.

All statistical analyses were performed using $R$ ( $R$ Foundation for Statistical Computing, Vienna, Austria; www.r-project.org) and Stata 10.1 (Stata Corporation, College Station, TX).

\section{Results}

The study population consisted of the 438 mother-child pairs for whom both prenatal $\mathrm{PM}_{2.5}, \mathrm{NO}_{2}$ and benzene exposure and neurodevelopment test results were available. Of the children, $54.8 \%$ were girls, $45.4 \%$ had siblings, $30.4 \%$ were breastfed for more than 6 months, $46.6 \%$ attended nursery school at the time of the assessment, $3.2 \%$ were preterm, $8.5 \%$ were small for their gestational age, and $4.3 \%$ had a low birth weight. With regard to the mothers' characteristics, $50.7 \%$ had at least completed secondary education, $50.2 \%$ were $30-34$ years of age at delivery, $42.0 \%$ belonged to the lower social class category (manual workers), $92.2 \%$ were Spanish, $77.6 \%$ had a healthy weight before pregnancy, and $23.1 \%$ were smokers at some point during the pregnancy (Table 1).

The children's mental scale score varied with sex of child and mother social class, scores being lower in boys and when the mother was classified in the lower social class category. The motor scores were lower among lower birth weight children and among those who were first offspring (Table 1). On the other hand, mental and motor scores were not associated with either maternal IQ, or levels of lead or mercury in umbilical cord blood or of dichlorodiphenyldichloroethylene (DDE) or polychlorinated biphenyls (PCBs; 138, 153 and 180) (assessed as individual congeners or the sum of their levels) in maternal blood.

The highest $\mathrm{PM}_{2.5}$ concentrations were recorded in the first year of follow-up (2006), while a decrease in the airborne particle concentration was observed during 2007 (results not shown). Tables S2, S3 and S4 detail the average $\mathrm{PM}_{2.5}, \mathrm{NO}_{2}$ and benzene levels and the correlations between pollutants, distances from the road and industries and exposure during each trimester of pregnancy and exposure during the whole pregnancy. A strong correlation was observed between trimesters and entire pregnancy; for this reason, we only considered wholepregnancy exposure in the rest of the analysis.

Table 2 presents the estimated changes in mental and motor scale scores associated with every $1 \mu \mathrm{g} / \mathrm{m}^{3}$ increase in $\mathrm{PM}_{2.5}, \mathrm{NO}_{2}$ and benzene. Comparing unadjusted estimates and adjusted estimates, moderate to high degree of confounding arose, in particular for the association between $\mathrm{PM}_{2.5}$ exposure and mental scale scores. As expected, child's age was one of the most relevant confounders, together with neuropsychologist (children were not randomly assigned to the neurologist and this casually generated a certain degree of confounding). After adjusting for covariates, including distances from roads and industries, we found that a $1 \mu \mathrm{g} / \mathrm{m}^{3}$ increase in $\mathrm{PM}_{2.5}$ was associated with a significant decrease of -1.14 points in motor scale $(90 \% \mathrm{CI}$ : $-1.76,-0.53 ; \mathrm{p}=0.002)$ and a decrease of -0.38 points in mental score $(-0.94,0.17 ; \mathrm{p}=0.254)$. Regarding $\mathrm{NO}_{2}$, we found a significant decrease of -0.29 points in mental scale $(-0.47,-0.11 ; \mathrm{p}=0.008)$ and a decrease of -0.14 point in motor scale $(-0.34 ; 0.06 ; \mathrm{p}=$ 0.259). Finally, benzene levels showed a negative, but non significant, associations with mental and motor scores both under the model 
Table 1

Associations between mental and motor scale scores and covariates related to the mothers and children $(n=438)$.

\begin{tabular}{|c|c|c|c|c|c|c|c|}
\hline & \multirow[t]{2}{*}{$\%$} & \multicolumn{3}{|c|}{ Mental scores } & \multicolumn{3}{|c|}{ Motor scores } \\
\hline & & Mean & Std. dev & p-Value & Mean & Std. dev & p-Value \\
\hline \multicolumn{8}{|l|}{ Child's sex } \\
\hline Female & 54.8 & 102.2 & $(14.7)$ & 0.009 & 100.8 & $(15.6)$ & 0.331 \\
\hline Male & 45.2 & 98.5 & $(14.6)$ & & 99.3 & $(14.8)$ & \\
\hline \multicolumn{8}{|c|}{ Preterm ( $<37$ weeks of gestation) } \\
\hline No & 96.8 & 100.7 & $(14.6)$ & 0.241 & 100.2 & $(15.3)$ & 0.266 \\
\hline Yes & 3.2 & 96.0 & $(16.6)$ & & 95.6 & $(15.4)$ & \\
\hline \multicolumn{8}{|c|}{ Low birth weight $(<2500 \mathrm{~g})$} \\
\hline No & 95.7 & 100.8 & $(14.7)$ & 0.078 & 100.4 & $(15.2)$ & 0.033 \\
\hline Yes & 4.3 & 94.7 & $(14.8)$ & & 92.8 & $(14.9)$ & \\
\hline \multicolumn{8}{|c|}{ Small for gestational age } \\
\hline No & 91.5 & 100.6 & $(14.7)$ & 0.977 & 100.1 & $(15.4)$ & 0.761 \\
\hline Yes & 8.5 & 100.6 & $(15.0)$ & & 99.3 & $(14.4)$ & \\
\hline \multicolumn{8}{|l|}{ Mother's age (years) } \\
\hline$<25$ & 1.8 & 101.3 & $(11.3)$ & 0.743 & 101.0 & $(11.1)$ & 0.979 \\
\hline$(25-<30)$ & 29.7 & 99.9 & $(13.1)$ & & 99.7 & $(15.4)$ & \\
\hline$(30-<35)$ & 50.2 & 101.2 & $(15.2)$ & & 100.3 & $(15.4)$ & \\
\hline$\geq 35$ & 18.3 & 99.9 & $(16.4)$ & & 100.4 & $(15.1)$ & \\
\hline \multicolumn{8}{|c|}{ Pre-pregnancy body mass index $\left(\mathrm{kg} / \mathrm{m}^{2}\right)$} \\
\hline $\begin{array}{c}\text { Underweight } \\
(<18.5)\end{array}$ & 3.9 & 98.5 & $(15.1)$ & 0.773 & 99.1 & $(16.4)$ & 0.188 \\
\hline Healthy $(>18.5-25)$ & 77.6 & 100.9 & $(14.7)$ & & 101.0 & $(14.3)$ & \\
\hline Overweight (>25-30) & 13.7 & 100.1 & $(14.9)$ & & 96.4 & $(18.7)$ & \\
\hline Obese $(>30)$ & 4.8 & 98.3 & $(13.8)$ & & 99.2 & $(16.3)$ & \\
\hline \multicolumn{8}{|c|}{ Maternal level of education } \\
\hline Primary school & 49.3 & 100.6 & $(14.7)$ & 0.765 & 100.7 & $(14.9)$ & 0.402 \\
\hline $\begin{array}{l}\text { High school/ } \\
\text { university degree }\end{array}$ & 50.7 & 100.4 & $(14.8)$ & & 99.5 & $(15.6)$ & \\
\hline \multicolumn{8}{|l|}{ Social class } \\
\hline Non-manual & 58.0 & 102.2 & $(14.7)$ & 0.005 & 100.5 & $(15.7)$ & 0.579 \\
\hline Manual & 42.0 & 98.2 & $(14.4)$ & & 99.6 & $(14.7)$ & \\
\hline \multicolumn{8}{|l|}{ Maternal parity } \\
\hline Primiparous & 54.6 & 100.5 & $(14.4)$ & 0.988 & 98.6 & $(14.9)$ & 0.024 \\
\hline$\geq 1$ & 45.4 & 100.6 & $(15.2)$ & & 101.9 & $(15.5)$ & \\
\hline \multicolumn{8}{|c|}{ Smoking during pregnancy (any trimester) } \\
\hline No & 76.9 & 100.1 & $(14.9)$ & 0.348 & 99.5 & $(15.2)$ & 0.240 \\
\hline Yes & 23.1 & 101.7 & $(14.3)$ & & 101.6 & $(15.6)$ & \\
\hline \multicolumn{8}{|c|}{ Cord blood Hg levels ( $\left.\mu \mathrm{g} / L, U_{S E P A^{\mathrm{a}}}\right)$} \\
\hline$<6.4$ & 30.1 & 100.4 & $(14.5)$ & 0.885 & 101.5 & $(14.8)$ & 0.203 \\
\hline$\geq 6.4$ & 69.9 & 100.6 & $(14.8)$ & & 99.5 & $(15.4)$ & \\
\hline \multicolumn{8}{|c|}{ Cord blood lead levels ( $\mu \mathrm{g} / \mathrm{dL})$} \\
\hline$<2$ & 96 & 100.8 & $(14.1)$ & 0.138 & 99.7 & $(15.2)$ & 0.092 \\
\hline$\geq 2$ & 4 & 106.1 & $(14.2)$ & & 106.2 & $(11.4)$ & \\
\hline \multicolumn{8}{|c|}{$\sum P C B s$ (third term of pregnancy) } \\
\hline$\leq 3$ rd tertile & 74.3 & 100.2 & $(14.4)$ & 0.439 & 100.5 & $(15.3)$ & 0.332 \\
\hline$>3$ rd tertile & 25.7 & 101.4 & $(15.2)$ & & 98.9 & $(15.3)$ & \\
\hline$p, p^{\prime}-D D E$ (third term & of preg & nancy) & & & & & \\
\hline$\leq 3$ rd tertile & 72.9 & 100.3 & $(14.5)$ & 0.668 & 99.8 & $(15.2)$ & 0.508 \\
\hline$>3$ rd tertile & 27.1 & 101.0 & $(14.9)$ & & 100.9 & $(15.7)$ & \\
\hline Maternal breastfeedir & & & & & & & \\
\hline $\begin{array}{l}\text { No breastfeeding } \\
\text { or } \leq 4 \text { months }\end{array}$ & 31.9 & 99.5 & $(14.7)$ & 0.546 & 99.7 & $(14.6)$ & 0.641 \\
\hline 4-6 months & 16.1 & 100.2 & $(14.3)$ & & 98.3 & $(16.2)$ & \\
\hline$>6$ months & 52 & 101.2 & $(15.0)$ & & 100.3 & $(15.4)$ & \\
\hline Attendance at nursery & & & & & & & \\
\hline No & 53.4 & 99.6 & $(14.8)$ & 0.174 & 100.3 & $(15.5)$ & 0.465 \\
\hline Yes & 46.6 & 101.6 & $(14.8)$ & & 99.1 & $(15.0)$ & \\
\hline Distance from PRTR & & & & & & & \\
\hline$\leq 100$ & 14.9 & 97.9 & $(13.2)$ & 0.331 & 99.5 & $(13.8)$ & 0.633 \\
\hline $100-300$ & 35.0 & 100.7 & $(14.6)$ & & 99.3 & $(15.3)$ & \\
\hline$>300$ & 50.1 & 101.0 & (14.9) & & 100.7 & $(15.5)$ & \\
\hline
\end{tabular}

Table 1 (continued)

\begin{tabular}{|c|c|c|c|c|c|c|c|}
\hline & \multirow[t]{2}{*}{$\%$} & \multicolumn{3}{|c|}{ Mental scores } & \multicolumn{3}{|c|}{ Motor scores } \\
\hline & & Mean & Std. dev & p-Value & Mean & Std. dev & p-Value \\
\hline \multicolumn{8}{|c|}{ Distance from traffic road ( $m$ ) } \\
\hline$\leq 100$ & 47.4 & 99.7 & $(13.8)$ & 0.215 & 99.0 & $(14.9)$ & 0.002 \\
\hline $100-300$ & 39.1 & 100.3 & $(15.2)$ & & 99.0 & $(15.5)$ & \\
\hline$>300$ & 13.5 & 103.4 & $(15.1)$ & & 106.4 & $(13.8)$ & \\
\hline
\end{tabular}

$\mathrm{p}, \mathrm{p}^{\prime}$-DDE $=\mathrm{p}, \mathrm{p}^{\prime}$-dichlorodiphenyldichloroethylene, $\mathrm{\Sigma} \mathrm{PCBs}=$ polychlorinated biphenyls, computed by the sum of congeners 138,153 , and 180; USEPA = U.S. Environmental Protection Agency.

a The USEPA reference dose was used as the threshold.

which did not account for distances and the model which accounted for them. Results from bipollutant models were similar to the results from the single-pollutant models.

\subsection{Subgroup analysis}

Certain evidence emerged showing that the association of $\mathrm{PM}_{2.5}$ and $\mathrm{NO}_{2}$ exposure with psychomotor and cognitive performance strengthened considering the subgroup of children that lived closest to the PRTR-listed facilities. Specifically, we estimated that in children living closest to industry $(<100 \mathrm{~m})$ a $1 \mu \mathrm{g} / \mathrm{m}^{3}$ increase in $\mathrm{PM}_{2.5}$ exposure was associated to a -3.20 variation in motor score $(90 \% \mathrm{CI}:-5.19$, -1.21 ) and a -2.72 variation in mental score (90\% CI: -4.69 , $-0.74)$. Estimated changes in scores for children living at larger distances were clearly lower, even if the test for interaction did not reject the null hypothesis of homogeneity among distance classes when a 5\% significance level was set (p-values for the interaction 0.177 , and 0.076 , respectively). For each $1 \mu \mathrm{g} / \mathrm{m}^{3}$ increase in $\mathrm{NO}_{2}$, mental score decreased -0.42 points $(90 \% \mathrm{CI}:-0.76,-0.06$ for distance $<100 ; 90 \% \mathrm{CI}$ : $-0.73,-0.11$ for distance $100-300)$. In the case of motor score, estimated changes were -0.51 ( $90 \% \mathrm{CI}:-0.89,-0.13),-0.42(90 \%$ CI: $-0.77,-0.08)$ and $0.34(90 \% \mathrm{CI}:-0.00,0.68)$ for distance $<100$, $100-300$ and $>300$, respectively; with p-value for the homogeneity test $<0.01$ (Table 3 ). Regarding distance from home to the nearest main road, there were not clear patterns. In the study area, we did not find differences in socio-economic status with the distance to the sources of pollution analysed. In fact, the distribution of the socioeconomic status was fairly homogeneous (data not shown).

Even the null hypothesis of effects homogeneity was not formally rejected, a weak evidence arose that breastfeeding could modify the associations between $\mathrm{PM}_{2.5}$ and $\mathrm{NO}_{2}$ exposure and mental scores ( $\mathrm{p}$ values for the interaction 0.106 and 0.228 , respectively). The change in mental score associated to $1 \mu \mathrm{g} / \mathrm{m}^{3}$ increase in $\mathrm{PM}_{2.5}$ was -0.03 $(-0.69,0.62)$ for children breastfed for more than 4 months and $-0.85(-0.15,-0.11)$ for children breastfed for 4 months or less. The change in mental score associated to $1 \mu \mathrm{g} / \mathrm{m}^{3}$ increase in $\mathrm{NO}_{2}$ was $-0.17(-0.41,0.07)$ for children breastfed for more than 4 months and $-0.40(-0.63,-0.17)$ for children breastfed for 4 months or less (Suppl Table S4). Association between air pollutant exposure and mental and motor scores did not vary according to maternal dietary antioxidant intake measured as fruit and vegetable consumption during pregnancy (Suppl Table S5). Any effect modification was found for benzene.

\section{Discussion}

In this birth cohort study, exposure to air pollutants during pregnancy was associated with a decrease in neuropsychological performance of 15-month-old children. In particular inverse and significant associations were found between: $\mathrm{PM}_{2.5}$ exposure and psychomotor performance and between $\mathrm{NO}_{2}$ exposure and cognitive performance. Benzene also showed inverse associations but the relationships were not statistically significant. These results were net of indicators of socioeconomic status 
Table 2

Estimated variations in mental and motor scale scores associated with $1 \mu \mathrm{g} / \mathrm{m}^{3}$ increase in the average level of $\mathrm{PM}_{2.5}, \mathrm{NO}_{2}$ and benzene during pregnancy.

\begin{tabular}{|c|c|c|c|c|c|c|c|}
\hline & \multirow[b]{2}{*}{ Model } & \multicolumn{3}{|c|}{ Mental scale score } & \multicolumn{3}{|c|}{ Motor scale score } \\
\hline & & Variation & $90 \% \mathrm{CI}$ & p-Value & Variation & $90 \% \mathrm{CI}$ & p-Value \\
\hline \multirow[t]{4}{*}{$\mathrm{PM}_{2.5}$} & Unadjusted & -0.70 & $-1.17,-0.23$ & 0.014 & -0.87 & $-1.36,-0.39$ & 0.003 \\
\hline & Adjusted M1 & -0.35 & $-0.88,0.18$ & 0.276 & -0.82 & $-1.41,-0.23$ & 0.021 \\
\hline & Adjusted M2 & -0.39 & $-0.95,0.17$ & 0.254 & -1.15 & $-1.76,-0.54$ & 0.002 \\
\hline & Bipollutant $\left(+\mathrm{NO}_{2}\right)$ & -0.35 & $-0.90,0.20$ & 0.295 & -1.13 & $-1.75,-0.52$ & 0.002 \\
\hline \multirow[t]{4}{*}{$\mathrm{NO}_{2}$} & Unadjusted & -0.28 & $-0.46,-0.11$ & 0.007 & -0.18 & $-0.36,0.0004$ & 0.102 \\
\hline & Adjusted 1 & -0.25 & $-0.40,-0.10$ & 0.007 & -0.14 & $-0.31,0.04$ & 0.195 \\
\hline & Adjusted 2 & -0.29 & $-0.47,-0.11$ & 0.008 & -0.14 & $-0.34,0.06$ & 0.259 \\
\hline & Bipollutant $\left(+\mathrm{PM}_{2.5}\right)$ & -0.29 & $-0.47,-0.11$ & 0.009 & -0.12 & $-0.32,0.08$ & 0.330 \\
\hline \multirow[t]{4}{*}{ Benzene } & Unadjusted & -4.17 & $-8.92,0.58$ & 0.149 & -6.14 & $-11.10,-1.18$ & 0.042 \\
\hline & Adjusted 1 & -3.36 & $-7.56,0.84$ & 0.188 & -3.93 & $-8.64,0.78$ & 0.170 \\
\hline & Adjusted 2 & -2.35 & $-8.46,3.75$ & 0.526 & -4.59 & $-11.42,2.24$ & 0.269 \\
\hline & Bipollutant $\left(+\mathrm{PM}_{2.5}\right)$ & -1.78 & $-8.04,4.48$ & 0.640 & -2.10 & $-9.06,4.85$ & 0.619 \\
\hline
\end{tabular}

Unadjusted model: Model that does not account for any confounder.

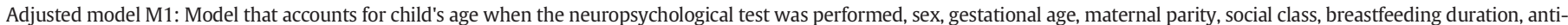
oxidant intake during pregnancy and neuropsychologist.

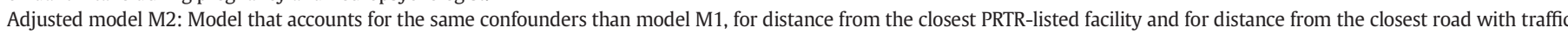
density $>20,000$ vehicles/day.

Bipollutant model: Model that accounts for the same confounders than model M2 and for a second air pollutant $\left(\mathrm{PM}_{2.5}\right.$ or $\left.\mathrm{NO}_{2}\right)$.

90\% CI: 90\% confidence interval for the variation in score.

p-Value: p-value of the Wald test for the null hypothesis of variation equal to zero (i.e. no association between average air pollutant level during pregnancy and child's score).

and other environmental factors known to affect neuropsychological development.

For both $\mathrm{NO}_{2}$ and $\mathrm{PM}_{2.5}$, the results from the bipollutant models were very similar to the results from the single-pollutant models, suggesting an independent effect of the two pollutants. In particular, our findings led us to conclude that in this study area $\mathrm{NO}_{2}$ cannot be considered only a proxy of $\mathrm{PM}_{2.5}$. On the contrary, the associations of both mental and psychomotor scores with benzene, although affected by large variability, appeared sensitive to the introduction in the model of the second air pollutant or of the distances from road and industry. This seems to suggest that benzene could simply be a marker of toxic air pollutants rather than a potential causative agent itself, as already suggested by Guxens et al. (2012a).

The results are suggestive of a possible effect modification by distance from home to the nearest PRTR-listed facility for both psychomotor and cognitive developments, with higher impairment for each $1 \mu \mathrm{g} / \mathrm{m}^{3}$ increase in $\mathrm{PM}_{2.5}$ and $\mathrm{NO}_{2}$ exposure among children whose mother had lived within a 100 -m radius during pregnancy. Regarding $\mathrm{PM}_{2.5}$, this result could be indicative of a different and more dangerous composition of small particles close to the industry. However, we cannot rule out the presence of other pollutants that could be correlated to $\mathrm{PM}_{2.5}$ and $\mathrm{NO}_{2}$ and affect children living close to industrial activities.

Table 3

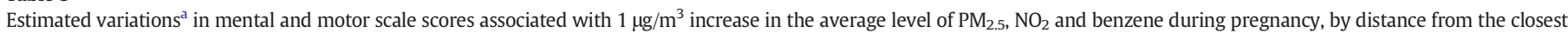
PRTR-listed facility and by distance from the closest road with traffic density $>20,000$ vehicles/day.

\begin{tabular}{|c|c|c|c|c|c|c|c|}
\hline & \multirow[t]{2}{*}{ Distance (m) } & \multicolumn{3}{|c|}{ Mental scale score } & \multicolumn{3}{|c|}{ Motor scale score } \\
\hline & & Variation & $90 \% \mathrm{CI}$ & p-Value & Variation & $90 \% \mathrm{CI}$ & p-Value \\
\hline \multirow[t]{8}{*}{$\mathrm{PM}_{2.5}$} & From PRTR & & & & & & \\
\hline & $\leq 100$ & -2.72 & $-4.70,-0.74$ & 0.076 & -3.20 & $-5.19,-1.21$ & 0.177 \\
\hline & $100-300$ & -0.98 & $-2.24,0.28$ & & -1.44 & $-2.84,-0.04$ & \\
\hline & $>300$ & -0.03 & $-0.68,0.61$ & & -0.86 & $-1.57,-0.14$ & \\
\hline & From road & & & & & & \\
\hline & $\leq 100$ & 0.11 & $-0.75,0.96$ & 0.374 & -1.10 & $-2.04,-0.17$ & 0.53 \\
\hline & $100-300$ & -0.99 & $-1.98,0.01$ & & -1.67 & $-2.80,-0.55$ & \\
\hline & $>300$ & -0.35 & $-1.50,0.79$ & & -0.56 & $-1.80,0.68$ & \\
\hline \multirow[t]{8}{*}{$\mathrm{NO}_{2}$} & From PRTR & & & & & & \\
\hline & $\leq 100$ & -0.42 & $-0.77,-0.07$ & 0.608 & -0.51 & $-0.89,-0.13$ & 0.008 \\
\hline & $100-300$ & -0.42 & $-0.73,-0.11$ & & -0.42 & $-0.77,-0.08$ & \\
\hline & $>300$ & -0.19 & $-0.49,0.12$ & & 0.34 & $-0.002,0.68$ & \\
\hline & From road & & & & & & \\
\hline & $\leq 100$ & -0.28 & $-0.52,-0.05$ & 0.917 & -0.19 & $-0.45,0.07$ & 0.606 \\
\hline & $100-300$ & -0.37 & $-0.66,-0.09$ & & -0.04 & $-0.36,0.28$ & \\
\hline & $>300$ & -0.36 & $-0.96,0.25$ & & 0.21 & $-0.47,0.89$ & \\
\hline \multirow{8}{*}{ Benzene } & From PRTR & & & & & & \\
\hline & $\leq 100$ & -2.52 & $-17.47,12.33$ & 0.672 & -10.89 & $-27.44,5.65$ & 0.391 \\
\hline & $100-300$ & -6.87 & $-16.67,2.92$ & & -10.92 & $-21.83,-0.01$ & \\
\hline & $>300$ & 0.48 & $-9.10,10.06$ & & 0.76 & $-9.93,11.46$ & \\
\hline & From road & & & & & & \\
\hline & $\leq 100$ & 1.03 & $-7.04,9.11$ & 0.505 & -6.17 & $-15.23,2.88$ & 0.748 \\
\hline & $100-300$ & -3.91 & $-11.42,3.60$ & & -1.79 & $-10.21,6.63$ & \\
\hline & $>300$ & -10.26 & $-28.48,7.96$ & & -0.14 & $-20.54,20.26$ & \\
\hline
\end{tabular}

90\% CI: 90\% confidence interval for the score variation.

p-Value: p-value of the F test for the null hypothesis of no interaction (i.e. homogeneity of the association in the three classes of distance).

a Estimated variations from models that account for child's age when the neuropsychological test was performed, sex, gestational age, maternal parity, social class, breastfeeding du-

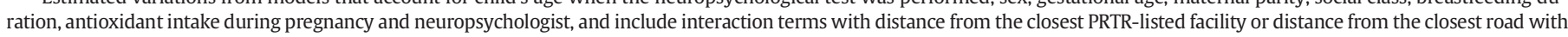
traffic density $>20,000$ vehicles/day. 
This could explain the fact that a significant interaction was found also for $\mathrm{NO}_{2}$.

Our study, that, to the best of our knowledge, is the first that explored the association between prenatal $\mathrm{PM}_{2.5}$ exposure and development in infants, contributes to the discussion about the role of air pollution in children development. Black carbon, a component of particulate matter coming mainly from traffic, has been associated with reductions in verbal and non-verbal intelligence and also with different memory constructs in 9-year-old children from Boston (Suglia et al., 2007); these authors considered the possibility of a transition metal producing neurotoxic effects. PAH air exposure, measured by personal monitoring during pregnancy, was also observed to adversely affect children's cognitive development at 5 years of age in a birth cohort in Poland (Edwards et al., 2010). Prenatal exposure to PAHs coming from emissions from a coal-burning power plant in China was analysed before and after the shutdown of the facility; negative effects on motor and language areas were observed in two years old children (Tang et al., 2008), and these effects were no longer seen in the children from a new cohort recruited after the plant had been shut down (Perera et al., 2008). PAH levels assessed in terms of PAH-DNA adducts in maternal blood have also been associated with a developmental delay (specifically lower mental scores) at 3 years of age (Perera et al., 2006) and reduced full-scale and verbal IQ at 5 years of age (Perera et al., 2009) in children of a birth cohort in New York.

Regarding $\mathrm{NO}_{2}$ exposure, published studies document an association of this pollutant with children cognitive and psychomotor developments. $\mathrm{NO}_{2}$, related to moderate traffic, was found to be associated with poorer performance in several motor and sensory domains in 8to 10-year-old children in Quanzhou, China (Wang et al., 2009). Similar results were also observed in a birth cohort from Granada (Spain) in 4year-old children (Freire et al., 2010). Recently, $\mathrm{NO}_{2}$ exposure during pregnancy was found to be associated with delayed motor development in 1 to 6-year-old children in six European birth cohorts, while mental development was not affected (Guxens et al., 2014).

The findings of the INMA birth cohorts in Spain, including the Guipúzcoa cohort, also support the view that prenatal residential exposure to $\mathrm{NO}_{2}$ and benzene may adversely affect infant cognitive development at 15 months of age (Guxens et al., 2012a). Although the levels of $\mathrm{NO}_{2}$ in Guipúzkoa were lower than those reported for the other cohorts (Guxens et al., 2012a), the results observed among infants from our cohort were clearly more adverse than those reported for the other Spanish cohorts and that finding was partly attributed to a more toxic mixture of air pollutants in the Guipúzkoa region due to the contribution of industrial sources (Guxens et al., 2012a). In relation to this, the high concentration of lead and manganese bound to $\mathrm{PM}_{2.5}$ found in the valleys where the Guipúzcoa cohort was recruited (Lertxundi et al., 2010) could underlie these adverse results, and this is an issue that needs to be explored in future research. Notably, in the present study, when we stratified the results by distance from PRTR-listed facilities, both $\mathrm{PM}_{2.5}$ and $\mathrm{NO}_{2}$, levels were significantly inversely associated with cognitive and psychomotor developments for children living closer than $100 \mathrm{~m}$ to the nearest PRTRlisted activity.

Regarding benzene, we were not able to fully confirm the inverse association with infant mental development estimated for the Guipúzcoa cohort by Guxens et al. (2012a). In fact, our study found an inverse association between benzene level and mental scale score, but the confidence interval around our estimate included the zero. This difference is likely due to the slightly lower sample size in our analysis than in Guxens et al. (for comparison reasons, we considered only the children for whom $\mathrm{PM}_{2.5}$ measurements were available). In fact, focusing on the results from the model which is closest to that adopted in Guxens et al., i.e. the model that did not account for distances from road and industry, one can note that the confidence interval is clearly shifted to negative values (variation: -3.36 ; $90 \% \mathrm{CI}$ : $-7.56,0.84$ ), and the $\mathrm{p}$-value is only moderately high (p-value: 0.188 ). Model differences, mainly concerning adjustment of confounding and shape of the exposureresponse curve, are expected to have a minor role in explaining the discrepancy between our result and the result reported in Guxens et al. (2012a).

From our findings certain evidence arose that duration of exclusive breastfeeding modified the association between mental scores and $\mathrm{PM}_{2.5}$ and $\mathrm{NO}_{2}$ exposure, being the association between exposure and mental development more evident when exclusive maternal breastfeeding was shorter than 4 months. No effect was observed for non-exclusive breastfeeding (data not shown).

Fruit and vegetable intake during pregnancy had been associated with a reduction of adverse effects of air pollutants on infant mental development in other INMA cohorts but not in Guipúzcoa (Guxens et al., 2012a). Consistently, our findings, including those for $\mathrm{PM}_{2.5}$, do not support the existence of a mitigation. The difference between the Guipúzcoa cohort and the other Spanish cohorts could be due to the high content of metals in particles in this region (Lertxundi et al., 2010), the damaging effects of which could not be mitigated by high antioxidant intake or detoxification factors, as already suggested by Guxens et al. (2012a).

One of the limitations of our study is the fact that for each woman, $\mathrm{PM}_{2.5}$ exposure during pregnancy was calculated using the $\mathrm{PM}_{2.5}$ levels measured at the monitoring site located in her town or in the closest one, due to the lack of measures at a finer spatial detail. We could not use a land-use regression (LUR) model to predict $\mathrm{PM}_{2.5}$ levels at each residence, as for $\mathrm{NO}_{2}$ and benzene. In fact, LUR performs well when measurements are available from a large number of monitors placed throughout the area of interest, but this would have been very expensive for $\mathrm{PM}_{2.5}$. However, it should be noticed that taking into account for distances from industry and road in the adjusted models, we partly corrected for possible misclassification of exposure, because associations were estimated being equal the distance from the main air pollution sources. A major problem in this study is due to the presence of a not negligible number of missing $\mathrm{PM}_{2.5}$ values due to the rotation of the monitors. We took advantage of the information from the fixed monitors in the region to fill in these missing values through a MI procedure, but, although MI is a powerful and advanced tool to treat missingness, the overall quality of our results could be partly affected by missingness.

Another limitation is related to the possibility that the observed effects could be partially related to the levels of air pollutant during early life and not only to prenatal exposures, given that prenatal and postnatal pollutants levels can reasonably be correlated. Moreover, we cannot exclude that the results are affected by confounding related to family context or parenting styles; this is a point to be considered in future researches.

Regarding future developments of the present work, we think that it would be interesting to explore whether the observed associations are maintained at later stages of the children's development. In fact, while the assessment of individual cognitive development at early ages is considered to have limited predictive value for future development at the individual level (Hess et al., 2004), early cognitive and especially motor developments have been correlated with the performance in older ages at the population level (Langkamp and Harris, 1992). Finally, the role of the exposure to specific chemical constituents of particles on children's development should be assessed, with the aim to help in development of more targeted policies of air pollution reduction.

\section{Conclusions}

This study suggests that prenatal residential exposure to $\mathrm{PM}_{2.5}$ and $\mathrm{NO}_{2}$ may adversely affect infant neuropsychological development and support a possible independent effect of the two contaminants. The effects of $\mathrm{PM}_{2.5}$ and $\mathrm{NO}_{2}$ on both psychomotor and cognitive developments early in life may be stronger in the proximity of metal processing 
plants, suggesting that the specific chemical composition of small particles from industrial sources and, more in general, the toxic mixture close to industrial emission sources should be taken into account to better understand the role of air pollution on neuropsychological development.

\section{Financial disclosure}

The authors declare that they have no current or potential competing financial interests.

\section{Financial support}

This study was funded by grants from Carlos III Health Institute and the Spanish Ministry of Health (Red INMA G03/176; FIS PI06/ 0867, FIS-PS09/00090), the Department of Health of the Basque Government (2005111093 and 2009111069), and the Provincial Government of Guipúzcoa (DFG06/004 and FG08/001). The funding organisations and sponsors had no role in the design or conduct of the study; the collection, management, analysis, or interpretation of the data; the preparation, review, or approval of the manuscript; or the decision to submit the manuscript for publication.

\section{Acknowledgements}

The authors would particularly like to thank all the participants for their generous collaboration. A full list of the INMA Project researchers can be found at http://www.proyectoinma.org/presentacion-inma/ listado-investigadores/en_listado-investigadores.html.

\section{Appendix A. Supplementary data}

Supplementary data to this article can be found online at http://dx.doi.org/10.1016/j.envint.2015.03.007.

\section{References}

Bayley, N., 1977. Bayley Scales of Infant Development. Psychological Corporation, San Antonio, TX.

Bolton, J.L., Huff, N.C., Smith, S.H., Mason, S.N., Foster, W.M., Auten, R.L., et al., 2013. Maternal stress and effects of prenatal air pollution on offspring mental health outcomes in mice. Environ. Health Perspect. 121, 1075-1082.

Calderón-Garcidueñas, L., Torres-Jardón, R., 2012. Air pollution, socioeconomic status, and children's cognition in megacities: the Mexico City Scenario. Front. Psychol. 3, 217.

Calderon-Garciduenas, L., Mora-Tiscareno, A., Ontiveros, E., Gomez-Garza, G., BarraganMejia, G., Broadway, J., et al., 2008. Air pollution, cognitive deficits and brain abnormalities: a pilot study with children and dogs. Brain Cogn. 68, 117-127.

Der, G., Batty, G.D., Deary, I.J., 2006. Effect of breast feeding on intelligence in children: prospective study, sibling pairs analysis, and meta-analysis. BMJ 333 (7575), 945.

Domingo-Salvany, A., Bacigalupe, A., Carrasco, J.M., Espelt, A., Ferrando, J., Borrell, C., 2013. Proposals for social class classification based on the Spanish National Classification of Occupations using neo-Weberian and neo-Marxist approaches. Gac. Sanit. 27 (3), 263-272.

Edwards, S.C., Jedrychowski, W., Butscher, M., Camann, D., Kieltyka, A., Mroz, E., et al., 2010. Prenatal exposure to airborne polycyclic aromatic hydrocarbons and children's intelligence at 5 years of age in a prospective cohort study in Poland. Environ. Health Perspect. 118, 1326-1331.

Freire, C., Ramos, R., Puertas, R., Lopez-Espinosa, M.J., Julvez, J., Aguilera, I., et al., 2010. Association of traffic-related air pollution with cognitive development in children. J. Epidemiol. Community Health 64, 223-228.

Grandjean, P., Landrigan, P.J., 2006. Developmental neurotoxicity of industrial chemicals. Lancet 368, 2167-2178.

Guxens, M., Aguilera, I., Ballester, F., Estarlich, M., Fernández-Somoano, A., Lertxundi, A. INMA (INfancia y Medio Ambiente) Project, et al., 2012a. Prenatal exposure to residential air pollution and infant mental development: modulation by antioxidants and detoxification factors. Environ. Health Perspect. 20 (1), 144-149.
Guxens, M., Ballester, F., Espada, M., Fernández, M.F., Grimalt, J.O., Ibarluzea, J., et al. 2012b. Cohort profile: the INMA - INfancia y Medio Ambiente - (Environment and Childhood) Project. Int. J. Epidemiol. 41 (4), 930-940.

Guxens, M., Garcia-Esteban, R., Giorgis-Allemand, L., Forns, J., Badaloni, C., Ballester, F., et al., 2014. Air pollution during pregnancy and childhood cognitive and psychomotor development: six European birth cohorts. Epidemiology 25 (5), 636-647.

Hackman, D.A., Farah, M.J., Meaney, M.J., 2010. Socioeconomic status and the brain: mechanistic insights from human and animal research. Nat. Rev. Neurosci. 11 (9), 651-659.

Hajat, A., Diez-Roux, A.V., Adar, S.D., Auchincloss, A.H., Lovasi, G.S., O'Neill, M.S., et al., 2013. Air pollution and individual and neighbourhood socioeconomic status: evidence from the Multi-Ethnic Study of Atherosclerosis (MESA). Environ. Health Perspect. 121, 1325-1333.

Hess, C.R., Papas, M.A., Black, M.M., 2004. Use of the Bayley Infant Neurodevelopmental Screener with an environmental risk group. J. Pediatr. Psychol. 29 (5), 321-330.

Ibarluzea, J., Alvarez-Pedrerol, M., Guxens, M., Marina, L.S., Basterrechea, M., Lertxundi, A. et al., 2011. Sociodemographic, reproductive and dietary predictors of organochlorine compounds levels in pregnant women in Spain. Chemosphere 82 (1), 114-120.

Iñiguez, C., Ballester, F., Estarlich, M., Llop, S., Fernandez-Patier, R., Aguirre-Alfaro, A., et al. 2009. Estimation of personal $\mathrm{NO}_{2}$ exposure in a cohort of pregnant women. Sci. Total Environ. 407, 6093-6099.

Kim, E., Park, H., Hong, Y.C. Ha, M., Kim, Y., Kim, B.N., et al., 2014. Prenatal exposure to $\mathrm{PM}_{10}$ and $\mathrm{NO}_{2}$ and children's neurodevelopment from birth to 24 months of age: Mothers and Children's Environmental Health (MOCEH) study. Sci. Total Environ. 481, 439-445 (May 15).

Langkamp, D.L., Harris, S., 1992. Predicting preschool motor and cognitive performance in appropriate-for-gestational-age children born at $\leq 32$ weeks gestation. Early Dev. Parenting 1 (2), 89-96.

Lertxundi, A., Martinez, M.D., Ayerdi, M., Alvarez, J., Ibarluzea, J.M., 2010. Air quality assessment in urban areas of Gipuzkoa (Spain). Gac. Sanit. 24, 187-192.

Li, F., Baccini, M., Mealli, F., Zell, E.Z., Frangakis, C.E., Rubin, D.B., 2014. Multiple imputation by ordered monotone blocks with application to the anthrax vaccine research program. J. Comput. Graph. Stat. 23 (3), 877-892.

Llop, S., Aguinagalde, X., Vioque, J., Ibarluzea, J., Guxens, M., Casas, M., et al., 2011. Prenatal exposure to lead in Spain: cord blood levels and associated factors. Sci. Total Environ. 409 (11), 2298-2305.

Perera, F.P., Rauh, V., Whyatt, R.M., Tsai, W.Y., Tang, D., Diaz, D., et al., 2006. Effect of prenatal exposure to airborne polycyclic aromatic hydrocarbons on neurodevelopment in the first 3 years of life among inner-city children. Environ. Health Perspect. 114, $1287-1292$.

Perera, F., Li, T.Y., Zhou, Z.J., Yuan, T., Chen, Y.H., Qu, L., et al., 2008. Benefits of reducing prenatal exposure to coal-burning pollutants to children's neurodevelopment in China. Environ. Health Perspect. 116, 1396-1400.

Perera, F.P., Li, Z., Whyatt, R., Hoepner, L., Wang, S., Camann, D., et al., 2009. Prenatal airborne polycyclic aromatic hydrocarbon exposure and child IQ at age 5 years. Pediatrics 124 (2), 195-202.

Ramon, R., Murcia, M., Aguinagalde, X., Amurrio, A., Llop, S., Ibarluzea, J., et al., 2011. Prenatal mercury exposure in a multicenter cohort study in Spain. Environ. Int. 37 (3), 597-604.

Siddique, S., Banerjee, M., Ray, M.R., Lahiri, T., 2011. Attention-deficit hyperactivity disorder in children chronically exposed to high level of vehicular pollution. Eur. J. Pediatr. 170 (7), 923-929.

Suglia, S.F., Gryparis, A., Wright, R.O., Schwartz, J., Wright, R.J., 2007. Association of black carbon with cognition among children in a prospective birth cohort study. Am. J. Epidemiol. 167 (3), 280-286.

Sunyer, J., 2008. The neurological effects of air pollution in children. Eur. Respir. J. 32 535-537.

Tang, D., Li, T.Y., Liu, J.J., Zhou, Z.J., Yuan, T., Chen, Y.H., et al., 2008. Effects of prenatal exposure to coal-burning pollutants on children's development in China. Environ. Health Perspect. 116, 674-679.

Van Buuren, S., Brand, J.P.L., Groothuis-Oudshoorn, C.G.M., Rubin, D.B., 2006. Fully conditional specifications in multivariate imputation. J. Stat. Comput. Simul. 76, 1049-1064.

Vioque, J., Weinbrenner, T., Asensio, L., Castello, A., Young, I.S., Fletcher, A., 2007. Plasma concentrations of carotenoids and vitamin $\mathrm{C}$ are better correlated with dietary intake in normal weight than overweight and obese elderly subjects. Br. J. Nutr. 97 977-986.

Volk, H.E., Lurmann, F., Penfold, B., Hertz-Picciotto, I., McConnell, R., 2013. Traffic-related air pollution, particulate matter, and autism. JAMA Psychiatry 70 (1), 71-77.

Walfisch, A., Sermer, C., Cressman, A., Koren, G., 2013. Breast milk and cognitive development-the role of confounders: a systematic review. BMJ Open 3, e003259. http://dx.doi.org/10.1136/bmjopen-2013-003259.

Wang, S., Zhang, J., Zeng, X., Zeng, Y., Wang, S., Chen, S., 2009. Association of traffic-related air pollution with children's neurobehavioral functions in Quanzhou, China. Environ. Health Perspect. 117, 1612-1618.

Wechsler, D., Kaufman, A., 2001. WAIS-III. Escala de inteligencia de Wechsler para adultos (III). Tea Ediciones, Madrid. 